\title{
Genomic characterization of JG068, a novel virulent podovirus active against Burkholderia cenocepacia
}

Karlene H Lynch ${ }^{1 \dagger}$, Ashraf H Abdu ${ }^{1+}$, Max Schobert ${ }^{2}$ and Jonathan J Dennis ${ }^{1 *}$

\begin{abstract}
Background: As is true for many other antibiotic-resistant Gram-negative pathogens, members of the Burkholderia cepacia complex (BCC) are currently being assessed for their susceptibility to phage therapy as an antimicrobial treatment. The objective of this study was to perform genomic and limited functional characterization of the novel BCC phage JG068 (vB_BceP_JG068).

Results: JG068 is a podovirus that forms large, clear plaques on Burkholderia cenocepacia K56-2. Host range analysis indicates that this phage can infect environmental, clinical, and epidemic isolates of Burkholderia multivorans, B. cenocepacia, Burkholderia stabilis, and Burkholderia dolosa, likely through interaction with the host lipopolysaccharide as a receptor. The JG068 chromosome is 41,604 base pairs (bp) in length and is flanked by 216 bp short direct terminal repeats. Gene expression originates from both host and phage promoters and is in the forward direction for all 49 open reading frames. The genome sequence shows similarity to Ralstonia phage $\phi R S B 1$, Caulobacter phage Cd1, and uncharacterized genetic loci of blood disease bacterium R229 and Burkholderia pseudomallei 1710b. CoreGenesUniqueGenes analysis indicates that JG068 belongs to the Autographivirinae subfamily and $\phi K M V-l i k e$ phages genus. Modules within the genome encode proteins involved in DNA-binding, morphogenesis, and lysis, but none associated with pathogenicity or lysogeny. Similar to the signal-arrest-release (SAR) endolysin of $\phi K M V$, inducible expression of the JG068 SAR endolysin causes lysis of Escherichia coli that is dependent on the presence of an N-terminal signal sequence. In an in vivo assay using the Galleria mellonella infection model, treatment of B. cenocepacia K56-2-infected larvae with JG068 results in a significant increase in larval survival.
\end{abstract}

Conclusions: As JG068 has a broad host range, does not encode virulence factors, is obligately lytic, and has activity against an epidemic B. cenocepacia strain in vivo, this phage is a highly promising candidate for BCC phage therapy development.

Keywords: Burkholderia cepacia complex, Phage therapy, Autographivirinae, фKMV-like phages, SAR endolysin, Galleria mellonella

\section{Background}

In recent years, the emergence of antibiotic-resistant Gram-negative pathogens - including Acinetobacter, Klebsiella, and Pseudomonas - has become a serious global concern [1]. As the treatment options for these bacteria become increasingly limited, scientists and clinicians

\footnotetext{
*Correspondence: jon.dennis@ualberta.ca

${ }^{+}$Equal contributors

'Department of Biological Sciences, 6-008 Centennial Centre for Interdisciplinary Science, University of Alberta, Edmonton, AB T6G 2E9 Canada

Full list of author information is available at the end of the article
}

alike have turned to bacteriophage (or phage) therapy as a possible alternative to antibiotic delivery. By preventing and/or treating infections with phages - viruses that specifically infect bacteria - one can target pathogens that are resistant to conventional drug treatment while avoiding possible antibiotic side effects, such as disruption of the patient's normal flora [2]. Phages infecting the Gram-negative bacteria Escherichia coli and Pseudomonas aeruginosa have already been shown to be safe for human administration in multiple volunteer and phase I trials [3-6]. Although relatively little data are currently available for controlled human efficacy studies, a recent

\section{Biomed Central}


phase I/II trial showed that $P$. aeruginosa-specific phages were clinically active [6].

The Burkholderia cepacia complex (BCC) is a group of antibiotic-resistant Gram-negative species that also appear to be a promising target for phage therapy. These bacteria cause transmissible and potentially fatal opportunistic infections in cystic fibrosis (CF) and immunocompromised patients. Similar to $P$. aeruginosa, BCC bacteria are innately antibiotic-resistant owing to a variety of mechanisms (reviewed in [7]). Antibiotics such as meropenem, minocycline, and ceftazidime show partial efficacy against some clinical isolates, but the vast majority of strains are not susceptible to even the administration of multiple drugs [8]. Although phage therapy for Burkholderia species has not yet reached clinical trials, preliminary studies have shown it to be safe and effective in the protection of crop seedlings and in both invertebrate and mammalian infection models [9-12].

One of the most important aspects of phage therapy development is the selection of appropriate therapeutic phage candidates. To be clinically applicable, a phage should have a broad host range (that includes clinical isolates) and a sequenced and characterized genome that lacks genes encoding putative pathogenicity factors and lysogeny-related proteins (reviewed in [13]). Identifying BCC-specific phages that meet all of the above criteria has thus far proven challenging, particularly with respect to lysogeny genes. Although several phages have been isolated and characterized that have a broad host range (encompassing multiple strains and species within the BCC) and no virulence genes, almost all of these phages are temperate or encode proteins required for this lifestyle $[13,14]$. BCC-specific phages that are obligately lytic (or putatively so) are thus far suboptimal for phage therapy development because they either infect only environmental isolates (Bcep1, Bcep43, Bcep781, and BcepB1A) [15] or have genomes that are either not sequenced or not published (KS12, BcepF1, BcepNazgul, BcepGomr, BcepEtu, BcepFife, and BcepBrny) [13,16]. Although we have shown that $\mathrm{BCC}$ phages can be engineered to an obligately lytic form, such mutants can be difficult to construct and could potentially encounter additional hurdles with respect to regulatory approval $[11,17]$. As a result of these obstacles, a key objective of BCC phage isolation and characterization studies is to isolate naturally occurring obligately lytic phages that infect clinical strains and lack putative virulence or lysogeny genes. Here, we describe and characterize the complete genome sequence of podovirus JG068, a novel phage possessing each of these characteristics. Furthermore, using a well-characterized invertebrate infection model $[10,18]$, we show that this phage is active against Burkholderia cenocepacia in vivo, providing further evidence that JG068 and other related phages are appropriate candidates for clinical development.

\section{Results and discussion}

\section{Isolation, host range, and morphology}

JG068 (vB_BceP_JG068) was isolated from a sewage processing plant using an uncharacterized strain of Burkholderia dolosa. Additional JG068 hosts were identified using spot tests and soft-agar overlays of BCC strains. A total of 32 strains were tested and seven were found to support lytic propagation of JG068 (with efficiency of plating [EOP] values in parentheses): Burkholderia multivorans ATCC $17616\left(10^{-4}\right)$, Burkholderia cenocepacia K56-2 $\left(10^{0}\right)$, J2315 $\left(10^{-2}\right)$, and PC184 $\left(10^{\circ}\right)$, Burkholderia stabilis LMG 14294 $\left(10^{-1}\right)$, and Burkholderia dolosa AU0158 $\left(10^{0}\right)$ and CEP021 $\left(10^{\circ}\right)$. Excluding the soil isolate ATCC 17616, each of these strains was identified as a CF clinical isolate [19-21]. Furthermore, the three susceptible B. cenocepacia strains and AU0158 have all been linked to epidemic spread among CF patients $[19,21]$. This host range is relatively broad, clinically relevant, and distinct compared to the tropism of BCC phages that we have previously characterized [10,11,22-26]. On K56-2, JG068 forms large clear plaques, $1-3 \mathrm{~mm}$ in diameter.

Several BCC phages - including KS4, KS5, KS9, KS10, and KS12 - have been previously shown to use lipopolysaccharide (LPS) as a receptor [11], Abdu and Juárez Lara, unpublished data]. To assess if JG068 uses a similar receptor, a panel of both K56-2 [27,28] and PC184 [Abdu, unpublished data] LPS mutants were tested with the phage in spot tests. In K56-2 mutants, JG068 (propagated on wildtype K56-2 [EOP: $10^{\circ}$ ]) less efficiently infected $w b x E$ and waaL mutants (EOP: $10^{-4}$ ) and did not infect $w a b R$, wabS, wabO, or waaC mutants (EOP: $<10^{-6}$; Table 1). In PC184 (EOP: $10^{\circ}$ ), this JG068 stock less efficiently infected a wabP mutant (EOP: $10^{-2}$ ) and did not infect $w a b O$ or waaC mutants (EOP: $<10^{-6}$; Table 1). As JG068 does not infect mutants with significant deficits in the core LPS structure, the tail of this phage likely interacts with the LPS core of K56-2, PC184, and potentially other hosts. As noted in a previous BCC phage study, further experiments are required to validate this prediction as LPS truncation may also result in secondary changes to the cell surface structure of the mutants [11,27].

Electron microscopy of JG068 virions (Figure 1) shows that this phage has a short tail and belongs to the C1 morphotype of the order Caudovirales and family Podoviridae [29]. This morphology is relatively rare for a BCC phage as the only Burkholderia podoviruses identified to date are the BPP-1-like BcepC6B and the Bcep22like DC1, Bcep22, BcepIL02, and BcepMigl [14]. The JG068 capsid is icosahedral and $60.93 \pm 2.83 \mathrm{~nm}$ in diameter (Figure 1).

\section{Genome sequencing and assembly}

In order to determine if the genome sequence of JG068 was novel, several EcoRI genomic DNA fragments were 
Table 1 JG068 LPS mutant host range

\begin{tabular}{|c|c|c|c|c|c|}
\hline B. cenocepacia strain & Mutant strain & Mutation & Reference & Phenotype & EOP \\
\hline \multirow[t]{7}{*}{$\mathrm{K} 56-2$} & wildtype & none & [19] & wildtype & $10^{0}$ \\
\hline & RSF19 & WbXE & {$[27]$} & truncated O-antigen & $10^{-4}$ \\
\hline & XOA7 & waal & {$[28]$} & no O-antigen & $10^{-4}$ \\
\hline & XOA15 & wabR & {$[28]$} & truncated outer core & $<10^{-6}$ \\
\hline & XOA17 & wabs & {$[28]$} & truncated outer core & $<10^{-6}$ \\
\hline & XOA8 & wabO & [28] & truncated inner core & $<10^{-6}$ \\
\hline & CCB1 & waac & {$[28]$} & truncated inner core & $<10^{-6}$ \\
\hline \multirow[t]{4}{*}{ PC184 } & wildtype & none & [19] & wildtype & $10^{0}$ \\
\hline & $\Delta w a b P$ & wabP & [Abdu, unpublished data] & truncated inner core & $10^{-2}$ \\
\hline & $\Delta w a b O$ & wabO & [Abdu, unpublished data] & truncated inner core & $<10^{-6}$ \\
\hline & $\Delta$ waac & waac & [Abdu, unpublished data] & truncated inner core & $<10^{-6}$ \\
\hline
\end{tabular}

cloned into pUC19 and sequenced. Resulting reads were analyzed using BLASTN and found to be similar (but not identical) to a variety of sequences, including those from previously characterized podoviruses. The genome sequence was completed using ion semiconductor technology on the Ion Torrent platform. A total of $1.07 \times 10^{5}$ sequence reads were aligned into a single contig with over 400-fold coverage. Regions of ambiguity and genome ends were analyzed using Sanger sequencing.

The JG068 genome is 41,604 bp in length and has a $60.7 \%$ GC content. Based on the similarity of the sequence to characterized $\phi \mathrm{KMV}$-like Autographivirinae genomes (discussed below), the chromosomal termini of JG068 are likely to be short direct terminal repeats (DTRs) as canonically found in T7 [30]. To identify these termini, JG068 DNA was directly sequenced using primers that bind the following four loci: within the left DTR,

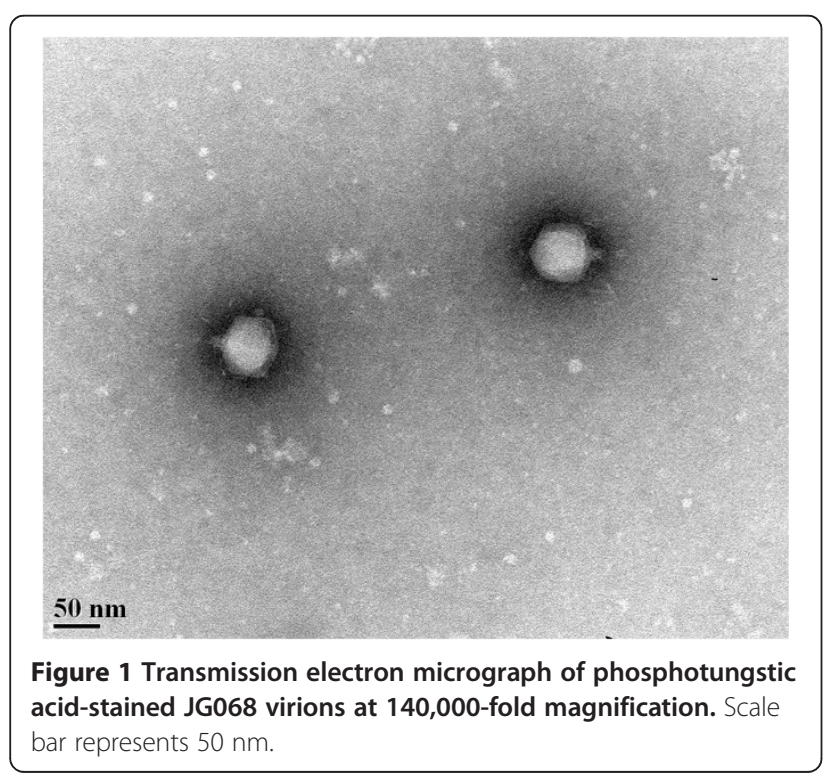

extending to the left terminus; immediately outside of the left DTR, extending to the left terminus; within the right DTR, extending to the right terminus; and immediately outside of the right DTR, extending to the right terminus. Primers that bind within the left DTR will amplify both the left and right ends of the genome simultaneously (as the primer binding site is in both DTRs). A reduction to onehalf intensity in the sequence chromatogram represents the arrest of half of the reads (those originating from the left end of the genome) at the left chromosome terminus [31]. Primers that bind immediately outside of the left DTR will amplify only the left end of the genome (as the primer binding site is unique) and the sequence chromatogram will stop abruptly at the left chromosome terminus [30]. The same reasoning is true for primers binding within or near the right DTR. Using these methods, it was determined that the chromosomal termini of JG068 are $216 \mathrm{bp}$ DTRs with an identical sequence on each end. The length of these repeats is shorter than that of other $\phi K M V-$ like Autographivirinae such as LKD16 (428 bp), $\phi K M V$ (414 bp), LKA1 (298 bp), and LIMElight (277 bp) [32-34].

In $\phi K M V$, genome replication is bidirectional with the origin and terminus in the DNA polymerase gene and an internal virion protein gene, respectively [33]. Using GenSkew analysis, a global co-minimum GC skew was identified in the JG068 DNA polymerase gene 18 and a global maximum skew was identified in the internal virion protein gene 38 , suggesting that the replication process of JG068 is similar to that of other $\phi K M V$-like Autographivirinae. In addition to the chromosomal termini and the putative replication origin, a third commonality with respect to the DNA of this genus of phages is that the JG068 genome lacks recognition sites for many common restriction enzymes, including BamHI, BglII, PstI, SacI, SmaI, and Xhol. As in other phages, including those that are $\phi K M V$-like, these sites tend to be lost as the phage evolves to avoid host restriction systems [32,33]. 


\section{Relatedness}

When the sequence of JG068 is analyzed using BLASTN, the most similar sequences (with E-values of $2 \mathrm{e}^{-87}$ or less) are those of Ralstonia phage $\phi R S B 1$, a genetic locus of blood disease bacterium R229, a genetic locus of Burkholderia pseudomallei 1710b chromosome 1, and Caulobacter phage Cd1. In the BLASTN results, JG068 shows similarity to several members of the Autographivirinae subfamily and $\phi K M V$-like phages genus, including $\phi R S B 1, \mathrm{Cd} 1$, and Pseudomonas phage Bf7. Members of this subfamily (with enterobacteria phage T7 being the best characterized) belong to one of several genera, including the T7-like phages, SP6-like phages, $\phi K M V-$ like phages, and novel genera that have not yet been named $[35,36]$. These podoviruses all encode a single subunit RNA polymerase, as is found in JG068 [35]. To determine if JG068 belongs to this subfamily (and, if so, to what genus), we used CoreGenesUniqueGenes (CGUG) analysis to compare the genomes of JG068, T7 (NC_001604.1), SP6

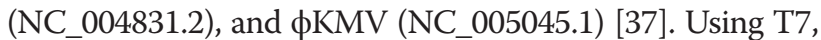
SP6, or $\phi K M V$ as the reference genome, the proteins of JG068 were $15.0 \%, 23.1 \%$, or $44.9 \%$ similar, respectively. As $\geq 40 \%$ similarity indicates a genus-level relationship [35], we can conclude that JG068 is a novel member of the Autographivirinae subfamily and the $\phi \mathrm{KMV}$-like phages genus. As noted above, the few BCC podoviruses that have been previously characterized are either Bcep22like or BPP-1-like [14], thus JG068 is the first BCC Autographivirinae phage to be identified.

\section{Genome annotation}

The JG068 genome contains 49 putative open reading frames (ORFs) (Figure 2, Table 2). Similar to T7 and other Autographivirinae, all of the genes are transcribed in the forward direction [33,38]. Based on BLASTP analysis (with an E-value cutoff of 0.01), 19 JG068 proteins show no similarity to other proteins in the database (Table 2). The remaining 30 proteins have percent identities between
29\% ( $\mathrm{Rz}$ protein gp48, similar to hypothetical protein Bpse9_41836 of B. pseudomallei 91) and 64\% (hypothetical protein gp8, similar to a hypothetical protein of Ralstonia phage RSB2) (Table 2), thus showing low-to-moderate similarity to other sequences at the protein level.

Similar to other phages, the JG068 genome has a modular organization. In both $\mathrm{T} 7$ and $\phi \mathrm{KMV}$, class I early genes are clustered on the left end of the genome, class II genes for DNA-binding proteins are found centrally, and class III genes for virion morphogenesis and lysis are positioned on the right end [32,38]. The overall organization of JG068 is syntenic with both of these phages: left end genes encode hypothetical proteins, central genes encode DNA-binding proteins, and right end genes encode capsid morphogenesis and DNA packaging, tail morphogenesis, and lysis proteins (Figure 2). Using BTXpred analysis (to identify toxins) combined with BLASTP and HHpred comparisons (to identify other pathogenicity-associated proteins; Tables 2 and 3), no putative virulence modules were detected, indicating that JG068 is likely to be a safe candidate for clinical testing.

A module commonly identified in other $\mathrm{BCC}$ phages that is notably absent from the JG068 genome is that for lysogeny. Similar to other obligately lytic phages, JG068 forms clear plaques and does not encode either an integrase or a repressor. Most other characterized members of the Autographivirinae are also virulent (although putative prophage elements described as being T7-like have been identified in Xanthomonas axonopodis, Pseudomonas putida, and B. pseudomallei) [39,40]. In order to verify experimentally that JG068 was not capable of lysogenizing BCC strains, we isolated JG068-insensitive K56-2 from a JG068/K56-2 lysate. To determine if these cells were insensitive due to either receptor mutation or superinfection immunity, we attempted to lyse these isolates using a second putatively virulent BCC-specific phage, KS12. Previous assays have shown that KS12 uses LPS as a receptor [Juárez Lara, unpublished data]. If JG068-insensitive K56-2

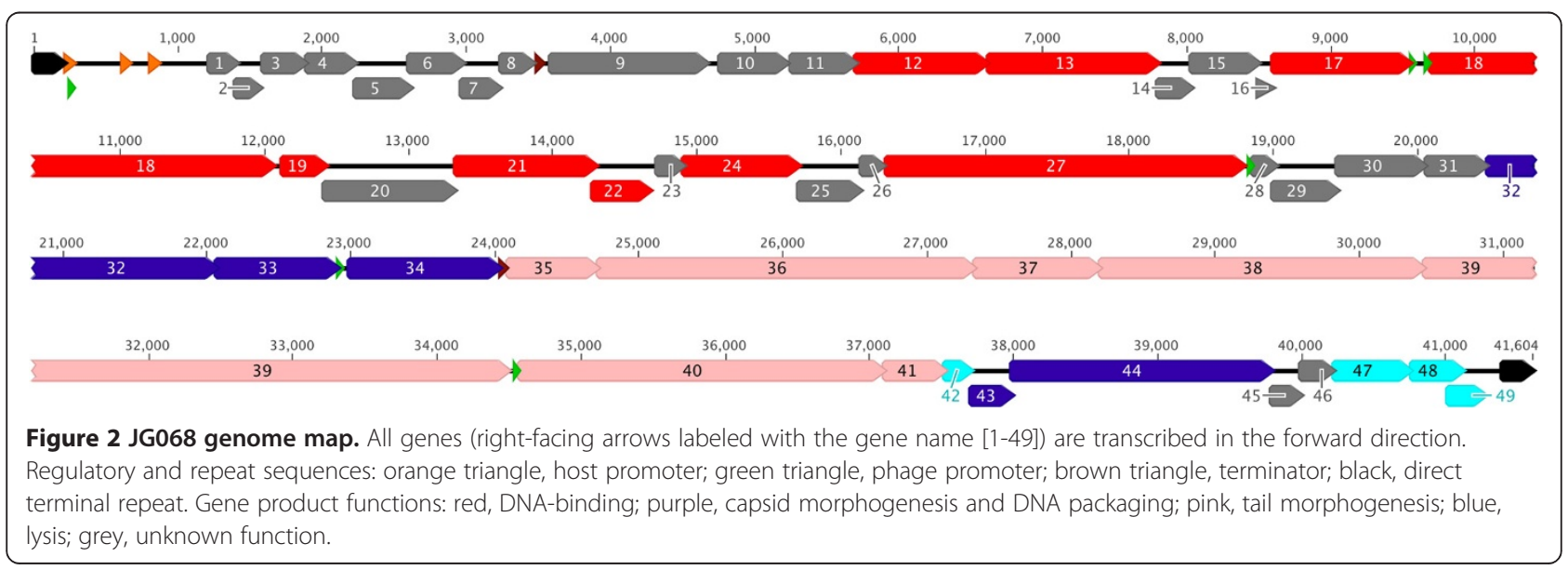


Table 2 JG068 genome annotation

\begin{tabular}{|c|c|c|c|c|c|c|c|c|c|c|c|c|}
\hline Gene & Start & End & Putative function & Strand & $\begin{array}{l}\text { Putative ribosome } \\
\text { binding site and } \\
\text { start codon }\end{array}$ & $\begin{array}{l}\text { Length } \\
\text { (amino acids) }\end{array}$ & Closest relative & $\begin{array}{l}\text { BLASTP alignment } \\
\text { region (amino acids) }\end{array}$ & $\begin{array}{l}\text { Percent } \\
\text { identity }\end{array}$ & E-value & Organism & $\begin{array}{l}\text { GenBank } \\
\text { accession } \\
\text { number }\end{array}$ \\
\hline 1 & 1211 & 1405 & hypothetical & + & ACGGAGctagacgaATG & 64 & none & & & & & \\
\hline 2 & 1402 & 1566 & hypothetical & + & GGAACGAtgctcgATG & 54 & none & & & & & \\
\hline 3 & 1590 & 1889 & hypothetical & + & GGAGTAAcgatcATG & 99 & $\begin{array}{l}\text { hypothetical protein } \\
\text { \$AB1_gp1 }\end{array}$ & $3-72 / 169$ & 50 & $1 e^{-13}$ & $\begin{array}{l}\text { Acinetobacter phage } \\
\text { ФA1 }\end{array}$ & ADQ12705.1 \\
\hline 4 & 1895 & 2227 & hypothetical & + & GGGGTGAGttcgATG & 110 & none & & & & & \\
\hline 5 & 2224 & 2613 & hypothetical & + & GGAGAAtcacGTG & 129 & $\begin{array}{l}\text { hypothetical protein } \\
\text { phAPEC8_0044 }\end{array}$ & $1-98 / 106$ & 32 & $6 e^{-8}$ & $\begin{array}{l}\text { Escherichia phage } \\
\text { phAPEC8 }\end{array}$ & AFU62620.1 \\
\hline 6 & 2603 & 2974 & hypothetical & + & GAGGTGttgaATG & 123 & none & & & & & \\
\hline 7 & 2971 & 3231 & hypothetical & + & AACGAGGccgcATG & 86 & none & & & & & \\
\hline 8 & 3242 & 3460 & hypothetical & + & AAGGAGcaacacATG & 72 & hypothetical protein & $27-54 / 109$ & 64 & $4 e^{-6}$ & $\begin{array}{l}\text { Ralstonia phage } \\
\text { RSB2 }\end{array}$ & BAJ51800.1 \\
\hline 9 & 3584 & 4672 & hypothetical & + & AGGACAtcaATG & 362 & none & & & & & \\
\hline 10 & 4762 & 5223 & hypothetical & + & AAGGAtttaacATG & 153 & none & & & & & \\
\hline 11 & 5252 & 5698 & hypothetical & + & AAGGAActgacATG & 148 & none & & & & & \\
\hline 12 & 5702 & 6610 & DNA primase & + & GGAGGctaaggcATG & 302 & $\begin{array}{l}\text { putative DnaG-like } \\
\text { primase }\end{array}$ & $1-277 / 284$ & 43 & $1 e^{-63}$ & $\begin{array}{l}\text { Caulobacter phage } \\
\text { Cd1 }\end{array}$ & ADD21651.1 \\
\hline 13 & 6624 & 7802 & DNA helicase & + & GAAGGTAAcacgcaaGTG & 392 & $\begin{array}{l}\text { hypothetical protein } \\
\text { BURPS1710b_1647 }\end{array}$ & $35-427 / 431$ & 61 & $2 e^{-176}$ & $\begin{array}{l}\text { Burkholderia } \\
\text { pseudomallei 1710b }\end{array}$ & YP_333051.1 \\
\hline 14 & 7802 & 8032 & hypothetical & + & GGGGGtgtgATG & 76 & none & & & & & \\
\hline 15 & 8032 & 8493 & hypothetical & + & AAGGAGGGtgcgtgATG & 153 & none & & & & & \\
\hline 16 & 8493 & 8603 & hypothetical & + & GTGGGGcgctgATG & 36 & none & & & & & \\
\hline 17 & 8600 & 9553 & DNA ligase & + & GGAGGAAggtATG & 317 & PBCV-1 DNA ligase & $4-309 / 309$ & 37 & $1 e^{-41}$ & $\begin{array}{l}\text { Burkholderia } \\
\text { pseudomallei } 91\end{array}$ & ZP_02453445.1 \\
\hline 18 & 9688 & 12060 & DNA polymerase & + & AAGGAAccATG & 790 & $38 \mathrm{~L}$ & $1-806 / 808$ & 60 & 0 & $\begin{array}{l}\text { Burkholderia } \\
\text { pseudomallei } 91\end{array}$ & ZP_02453448.1 \\
\hline 19 & 12122 & 12424 & $\mathrm{HNH}$ endonuclease & + & AGGCAcggtcgcagcATG & 100 & endonuclease & $30-112 / 249$ & 47 & $7 e^{-18}$ & $\begin{array}{l}\text { Bacteroides finegoldii } \\
\text { DSM } 17565\end{array}$ & ZP_05414969.1 \\
\hline 20 & 12421 & 13314 & hypothetical & + & AAGGAAcaagtATG & 297 & $37 \mathrm{~L}$ & $8-260 / 276$ & 50 & $7 e^{-71}$ & $\begin{array}{l}\text { Burkholderia } \\
\text { pseudomallei } 91\end{array}$ & ZP_02453449.1 \\
\hline 21 & 13327 & 14301 & DNA exonuclease & + & AAGGAGGcaaggccATG & 324 & phosphodiesterase I & $1-247 / 258$ & 48 & $5 e^{-75}$ & $\begin{array}{l}\text { Burkholderia } \\
\text { pseudomallei 1710a }\end{array}$ & ZP_04951398.1 \\
\hline 22 & 14282 & 14677 & DNA endonuclease & + & ATGAGAttgaccacaagcATG & 131 & DNA endonuclease VII & $1-115 / 118$ & 47 & $2 e^{-28}$ & $\begin{array}{l}\text { blood disease } \\
\text { bacterium R229 }\end{array}$ & CCA83273.1 \\
\hline 23 & 14727 & 14909 & hypothetical & + & GGCAGGttgattgcATG & 60 & none & & & & & \\
\hline 24 & 14910 & 15704 & DNA exonuclease & + & GGAGAttaaATG & 264 & $34 \mathrm{~L}$ & $1-263 / 263$ & 60 & $1 e^{-115}$ & $\begin{array}{l}\text { Burkholderia } \\
\text { pseudomallei } 91\end{array}$ & ZP_02453452.1 \\
\hline
\end{tabular}


Table 2 JG068 genome annotation (Continued)

\begin{tabular}{|c|c|c|c|c|c|c|c|c|}
\hline 25 & 15704 & 16138 & hypothetical & + & GGTGAGctaATG & 144 & hypothetical protein & $16-128 / 138$ \\
\hline 26 & 16142 & 16297 & hypothetical & + & GACGGAGtaacagATG & 51 & none & \\
\hline 27 & 16313 & 18799 & RNA polymerase & + & GAGGAcactgATG & 828 & $\begin{array}{l}\text { DNA-directed RNA } \\
\text { polymerase }\end{array}$ & $6-817 / 818$ \\
\hline 28 & 18861 & 19025 & hypothetical & + & AAGGAAccgGTG & 54 & none & \\
\hline 29 & 19003 & 19443 & hypothetical & + & AAGGAActgcgcgATG & 146 & $\begin{array}{l}\text { hypothetical protein } \\
\text { BDB_mp60445 }\end{array}$ & $1-143 / 145$ \\
\hline 30 & 19444 & 20058 & hypothetical & + & AAGGAGAtttgaATG & 204 & none & \\
\hline 31 & 20068 & 20478 & hypothetical & + & AAGGAGGGagcATG & 136 & none & \\
\hline 32 & 20488 & 22065 & $\begin{array}{l}\text { head-tail connector } \\
\text { protein }\end{array}$ & + & AAGGAGAAgacATG & 525 & $\begin{array}{l}\text { head portal-like protein } \\
\text { from phage }\end{array}$ & $9-494 / 512$ \\
\hline 33 & 22066 & 22908 & $\begin{array}{l}\text { scaffolding } \\
\text { protein }\end{array}$ & + & AAGGAGcgtaaATG & 280 & $\begin{array}{l}\text { scaffolding-like protein } \\
\text { from phage }\end{array}$ & $59-249 / 255$ \\
\hline 34 & 22991 & 24031 & capsid protein & + & AGGAGGAAcctcaATG & 346 & $\begin{array}{l}\text { major capsid-like } \\
\text { protein }\end{array}$ & $8-336 / 336$ \\
\hline 35 & 24099 & 24716 & $\begin{array}{l}\text { tail tubular } \\
\text { protein A }\end{array}$ & + & AAGGAGActgctATG & 205 & $\begin{array}{l}\text { tail tuber protein } \mathrm{A} \\
\text { from phage }\end{array}$ & $1-200 / 203$ \\
\hline 36 & 24726 & 27326 & $\begin{array}{l}\text { tail tubular } \\
\text { protein B }\end{array}$ & + & AAGGAGGcattATG & 866 & $\begin{array}{l}\text { tail tuber protein } B \\
\text { from phage }\end{array}$ & $2-858 / 858$ \\
\hline 37 & 27339 & 28196 & $\begin{array}{l}\text { internal virion } \\
\text { protein }\end{array}$ & + & AAGGGGGGtcagtcATG & 285 & $\begin{array}{l}\text { hypothetical protein } \\
\text { Bpse38_32600 }\end{array}$ & $5-199 / 301$ \\
\hline 38 & 28206 & 30446 & $\begin{array}{l}\text { internal virion } \\
\text { protein }\end{array}$ & + & AAGGAGGtagcATG & 746 & $\begin{array}{l}\text { hypothetical protein } \\
\text { RSB1_gp36 }\end{array}$ & $1-361 / 785$ \\
\hline 39 & 30458 & 34495 & $\begin{array}{l}\text { internal virion } \\
\text { protein }\end{array}$ & + & AAAGGAGAAGtaaATG & 1345 & internal virion protein & $9-1318 / 1333$ \\
\hline 40 & 34572 & 37097 & tail fiber protein & + & AGGAGGcaacATG & 841 & BcepGomrgp19 & $\begin{array}{l}307-539 \\
321-459 / 669\end{array}$ \\
\hline 41 & 37107 & 37520 & $\begin{array}{l}\text { tail fiber assembly } \\
\text { protein }\end{array}$ & + & AAGGAGGttttATG & 137 & $\begin{array}{l}\text { hypothetical protein } \\
\text { Bcep1808_1285 }\end{array}$ & $7-141 / 146$ \\
\hline 42 & 37524 & 37706 & holin & + & AGGAGtaagtaATG & 60 & none & \\
\hline 43 & 37703 & 37987 & DNA maturase A & + & AGGAGcaagctATG & 94 & $\begin{array}{l}\text { conserved hypothetical } \\
\text { protein from phage }\end{array}$ & $6-79 / 96$ \\
\hline 44 & 37989 & 39788 & DNA maturase $B$ & + & GAGGCAttgatATG & 599 & $\begin{array}{l}\text { TerL large terminase } \\
\text { subunit-like protein }\end{array}$ & $4-604 / 605$ \\
\hline 45 & 39788 & 39994 & hypothetical & + & GGAGGAAgtaATG & 68 & none & \\
\hline 46 & 39998 & 40222 & hypothetical & + & AAAGGAGtaattcATG & 74 & none & \\
\hline
\end{tabular}

Pantoea phage YP_007002888.1 LIMElight

\begin{tabular}{|c|c|c|c|}
\hline 33 & $5 e^{-6}$ & $\begin{array}{l}\text { Pantoea phage } \\
\text { LIMElight }\end{array}$ & YP_007002888.1 \\
\hline 51 & 0 & $\begin{array}{l}\text { Burkholderia } \\
\text { thailandensis } \\
\text { MSMB43 }\end{array}$ & ZP_02468154.1 \\
\hline 35 & $5 e^{-18}$ & $\begin{array}{l}\text { blood disease } \\
\text { bacterium R229 }\end{array}$ & CCA83279.1 \\
\hline 50 & $1 e^{-165}$ & $\begin{array}{l}\text { blood disease } \\
\text { bacterium R229 }\end{array}$ & CCA83282.1 \\
\hline 36 & $2 e^{-18}$ & $\begin{array}{l}\text { blood disease } \\
\text { bacterium R229 }\end{array}$ & CCA83283.1 \\
\hline 57 & $6 e^{-133}$ & $\begin{array}{l}\text { Ralstonia phage } \\
\text { RSB1 }\end{array}$ & YP_002213721.1 \\
\hline 40 & $9 e^{-42}$ & $\begin{array}{l}\text { blood disease } \\
\text { bacterium R229 }\end{array}$ & CCA83285.1 \\
\hline 48 & 0 & $\begin{array}{l}\text { blood disease } \\
\text { bacterium R229 }\end{array}$ & CCA83286.1 \\
\hline 37 & $8 e^{-22}$ & $\begin{array}{l}\text { Burkholderia } \\
\text { thailandensis } \\
\text { MSMB43 }\end{array}$ & ZP_02468144.1 \\
\hline 30 & $2 e^{-42}$ & $\begin{array}{l}\text { Ralstonia phage } \\
\text { RSB1 }\end{array}$ & YP_002213725.1 \\
\hline 30 & $2 e^{-131}$ & $\begin{array}{l}\text { Caulobacter phage } \\
\mathrm{Cd} 1\end{array}$ & ADD21673.1 \\
\hline 44,31 & $\begin{array}{l}3 e^{-44} \\
2 e^{-5}\end{array}$ & $\begin{array}{l}\text { Burkholderia phage } \\
\text { BcepGomr }\end{array}$ & YP_001210239.1 \\
\hline 41 & $2 e^{-28}$ & $\begin{array}{l}\text { Burkholderia } \\
\text { vietnamiensis G4 }\end{array}$ & YP_001119130.1 \\
\hline 44 & $2 e^{-11}$ & $\begin{array}{l}\text { blood disease } \\
\text { bacterium R229 }\end{array}$ & CCA83292.1 \\
\hline 59 & 0 & $\begin{array}{l}\text { Ralstonia phage } \\
\text { RSB1 }\end{array}$ & YP_002213730.1 \\
\hline
\end{tabular}


Table 2 JG068 genome annotation (Continued)

$47 \quad 4023240753$ SAR endolysin + $\quad$ AAGGAGGcagcATG

phage-type lysozyme $\quad 68-211 / 223$

36

$8 e^{-27}$

Xanthomonas

phage Xp10

NP_858975.1

$484076341119 \mathrm{Rz}$

AGGAGAtaaccATG

118

hypothetical protein $\quad 5-105 / 106$

Bpse9_41836

29

$6 e^{-4}$

Burkholderia

ZP_02453410.1

$49 \quad 41016 \quad 41267 \quad$ Rz1

AAGGGGAAGctgaATG

83

exported hypothetical $\quad$ 18-79/83

pseudomallei 91

protein

$4 \mathrm{e}^{-11} \quad$ blood disease

bacterium R229

CCA83297.1

BLASTP hits with an E-value $<0.01$ were included in the table. 
Table 3 JG068 HHpred predictions

\begin{tabular}{lllll}
\hline Protein & Motif of closest relative & Motif definition & Percent probability & E-value \\
\hline gp12 & 2au3_A & DNA primase & 100 & 100 \\
gp13 & 3bgw_A & DNAB-like replicative helicase & 93.88 & $1.10 e^{-42}$ \\
gp15 & 1v58_A & Thiol:disulfide interchange protein DSBG & 100 & 0.13 \\
gp17 & 1fvi_A & Chlorella virus DNA ligase-adenylate & 100 & $3.90 e^{-60}$ \\
gp18 & 3pv8_A & DNA polymerase I & 99.92 & $1.60 e^{-113}$ \\
gp19 & 1u3e_M & HNH homing endonuclease & 100 & $2.90 e^{-25}$ \\
gp21 & 1exn_A & 5'-exonuclease, 5'-nuclease & 100 \\
gp22 & 1e7l_A & GP49, recombination endonuclease VII & 99.85 \\
gp24 & 2gui_A & DNA polymerase III epsilon subunit & 100 \\
gp27 & 1msw_D & DNA-directed RNA polymerase, bacteriophage T7 RNA & $3.90 e^{-54}$ \\
gp29 & 4h89_A & GCN5-related N-acetyltransferase & 96.86 \\
gp32 & 3lj5_A & Portal protein, protein GP1 & 96.82 \\
gp34 & 2xd8_A & GP10, T7-like capsid protein & 100 \\
gp39 & 1qsa_A & Protein (soluble lytic transglycosylase SLT70) & $9.10 e^{-42}$ \\
gp40 & 2ch7_A & Methyl-accepting chemotaxis protein & 99.15 \\
gp41 & 2kz6_A & Uncharacterized protein & 96.27 \\
gp44 & 3cpe_A & Terminase, DNA packaging protein GP17 & $2.30 e^{-21}$ \\
gp47 & 3hde_A & Lysozyme & 99.67 & 0.002 \\
\hline
\end{tabular}

HHpred hits with a probability $>90 \%$ were included in the table.

isolates are also insensitive to KS12 infection, they are likely LPS mutants, whereas if they are sensitive to KS12 infection, they are likely JG068 lysogens. Over 100 JG068insensitive isolates were screened and all were found to be insensitive to both phages compared to wildtype K562. Twelve resistant colonies were PCR-screened using JG068-specific primers and each isolate was found to be amplification-negative. This evidence shows that resistance arises due to receptor mutation and not due to JG068 lysogeny.

In Autographivirinae, transcription is first initiated from host promoters found at the far left-hand side of the genome, followed by initiation from phage RNA polymerase-specific promoters found throughout the genome [33,38]. JG068 promoters putatively recognized by BCC RNA polymerase were identified using Neural Network Promoter Prediction. Using a cutoff of 0.95 and limiting the results to sequences found intergenically, three promoters were identified in the first $650 \mathrm{bp}$ downstream of the left DTR (Figure 2 and Figure 3A). Phage promoters lack the conserved structure observed in bacterial promoters with -10 and -35 regions and are instead described as short consensus sequences that vary among different phages [41]. PHIRE was used to identify a strongly conserved $16 \mathrm{bp}$ consensus sequence (Figure 3B) found six times at five intergenic loci in the JG068 chromosome: overlapping the first host promoter sequence, upstream of the DNA polymerase gene 18
(2 promoters), upstream of the hypothetical protein gene 28 (downstream of the DNA-binding module), upstream of the capsid gene 34, and upstream of the tail fiber gene 40 (Figure 2). Putative rho-independent terminators were identified using TransTermHP. Although multiple sequences were reported in the output, those shown in Figure 3C were chosen because they were intergenic (based on GeneMark predictions) and had a $\Delta G$ value of $-10 \mathrm{kcal} / \mathrm{mol}$ or less. Similar to LIMEzero, the putative terminators are found upstream of the DNA-binding module and downstream of the capsid protein (Figure 2) [34].

\section{Module analysis \\ DNA-binding proteins}

One of the more notable aspects of the JG068 genome is its abundance of DNA-binding proteins. As discussed above, similar to $\mathrm{T} 7$ and $\phi \mathrm{KMV}$, these genes are found centrally in the JG068 genome (Figure 2). In JG068 and other $\phi K M V-$ like phages [32-34], the RNA polymerase gene is at the far right end of this module (upstream of the structural genes; Figure 2), whereas in T7 it is found close to the left end of the genome [38]. JG068 DNAbinding proteins include the primase gp12, helicase gp13, ligase gp17, DNA polymerase gp18, HNH endonuclease gp19, exonuclease gp21, endonuclease gp22, exonuclease gp24, and RNA polymerase gp27 (Table 2). The annotation of each of these proteins was based 


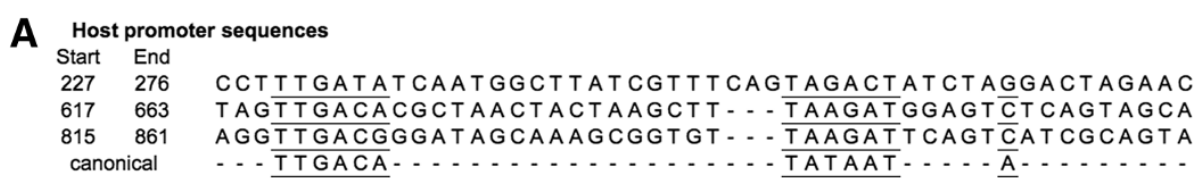

B Phage promoter sequences

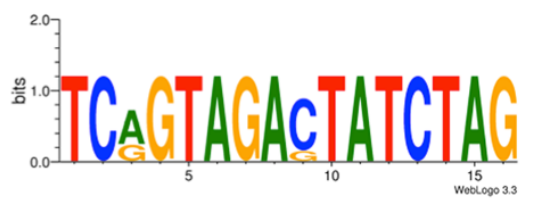

C Rho-independent terminator sequences

Start End

34923523 CGCAGCGGGCGTCG - TCT T - CGGT GCCACCTGCGTATCT

2404024070 TAGCCCCGCTT C C - CACAA- GGAGGTGGGGCT ATTTT

Figure 3 Predicted promoter and terminator sequences in JG068. A, putative host promoter sequences identified using Neural Network Promoter Prediction [50]. Predicted $-35 /-10$ boxes and transcription start sites are underlined. A canonical prokaryotic promoter is shown below. B, putative phage promoter consensus sequence identified using PHIRE [51] and plotted using WebLogo 3.3 [52]. C, putative rho-independent terminator sequences identified using TransTermHP [53]. The central loop region is separated by dashes and the 3' stretch of thymidine residues is underlined.

on BLASTP analysis and subsequently confirmed using HHpred (Tables 2 and 3).

One of the unifying features of the Autographivirinae is the presence of a single-subunit phage RNA polymerase gene [35]. Based on CGUG analysis, the only JG068 DNA-binding protein that shows similarity to those of T7 is this polymerase. These two proteins have $31 \%$ identity based on BLASTP analysis. In contrast, almost all of the JG068 DNA-binding proteins are similar to proteins in фKMV with $29-48 \%$ identity. Furthermore, these genes are found in the same order in these two phages.

The three components within this module that are dissimilar between \$KMV and JG068 are the genes encoding the ligase, $\mathrm{HNH}$ endonuclease, and DNA binding protein. In $\phi K M V$, a ligase gene is found between the helicase and DNA polymerase (as in JG068), but the sequences of these genes are dissimilar between the two phages [32]. Several HNH homing endonuclease genes have been identified in T7 [38], but only one is found in JG068 and none have been identified in $\phi \mathrm{KMV}$. Although a DNA binding protein gene was identified upstream of the helicase gene in $\phi K M V$ [32], such a gene was not identified in the JG068 annotation.

The position of the promoters driving the expression of genes in this module also differs between these phages. In $\phi K M V$, promoters upstream of these genes include four host promoters and two phage promoters (one between the DNA binding protein and primase genes and one between the DNA polymerase and endonuclease genes) [32]. In contrast, whereas the host promoters for JG068 are found at a similar locus as in $\phi K M V$, the phage promoters either overlap the host promoters or are found between the ligase (17) and DNA polymerase (18) genes (Figure 2). Based on this arrangement, all of the $\phi K M V$ genes in this module could be expressed from internal phage promoters (except for the gene encoding the DNA binding protein), whereas the primase (12), helicase (13), and ligase (17) genes of JG068 would be expressed from either a host promoter or the nested phage promoter on the far left end (Figure 2).

\section{Morphogenesis proteins}

The structural proteins of $\phi K M V$, LKA1, and LKD16 have been identified using mass spectrometry of proteins from purified virions [33,42]. Based on CGUG analysis, JG068 encodes proteins similar to the majority of these structural proteins. The putative structural genes $32-40$ (excluding 33, discussed below) are contained in a single $17 \mathrm{kbp}$ module (Figure 2). In a CGUG comparison of $\phi K M V$ and JG068, the head-tail connector (JG068 gp32), capsid protein (gp34), tail tubular protein A (gp35) and B (gp36), internal virion proteins (gp38 and gp39), and tail fiber protein (gp40) are all similar and each of these proteins was shown to be structural in $\phi K M V$ virions [42]. In addition, when JG068 and LKA1 are compared using CGUG, a third internal virion protein (gp37) is identified as similar that is structural in LKA1 [33]. $\phi K M V$, LKA1, and LKD16 virions also contain some proteins not encoded similarly by JG068. The genes encoding these structural proteins are found either upstream of the head-tail connector gene or downstream of the tail fiber gene and have uncharacterized functions or are putatively involved in adsorption [33,42]. Based on our genome annotation, JG068 does not encode any additional unique structural proteins.

Additional head morphogenesis/DNA packaging and tail morphogenesis proteins are encoded by JG068 that are not predicted to be associated with the mature virion. 
Although the scaffolding protein gp33 is encoded within the structural module discussed above, it is likely to function in capsid assembly but not to be part of the mature virion based on $\phi K M V$, LKA1, and LKD16 structural protein analysis $[33,42]$. Dissimilar to many other phages (but similar to others in the $\phi K M V$-like genus) [32-34], the DNA packaging genes 43 and 44 are found far downstream of the head morphogenesis genes (Figure 2). Gp33, gp43, and gp44 are all similar to proteins of $\phi K M V$ based on CGUG analysis. The only putative morphogenesis protein that is unique to JG068 and not shared by $\phi K M V$ or LKA1 is the putative tail fiber assembly protein gp41. Although HHpred analysis was uninformative (as the high probability matches to gp41 lack characterized functions; Table 3), this protein shows similarity in BLASTP analysis to tail fiber assembly proteins of Cupriavidus necator N-1, Dickeya dadantii 3937, and Idiomarina xiamenensis 10-D-4.

\section{Lysis proteins}

The lysis proteins of JG068, encoded on the far right end of the genome, include a putative pinholin, signalarrest-release (SAR) endolysin, Rz, and Rz1. Although the lysis genes in most phages (including $\phi K M V$ ) tend to be arranged in a single block with the holin gene followed by the endolysin, Rz, and Rz1 genes [43], this order is not maintained in JG068. Here, the putative pinholin gene 42 is found upstream of the SAR endolysin (47), Rz (48), and Rz1 (49) genes, separated by genes encoding two DNA packaging proteins and two hypothetical proteins (Figure 2). Within the Autographivirinae subfamily, this gene arrangement is also observed in SP6 [44].

Although only two of the four JG068 lysis proteins are similar to those of $\phi K M V$ based on CGUG analysis (the SAR endolysin gp47 and Rz gp48), these two phages are likely to use similar lysis mechanisms. The gp42 pinholin has analogous features to that of $\phi K M V: \sim 60$ amino acids in length (60 for JG068 and 66 for $\phi K M V)$, two transmembrane domains (as predicted by TMHMM analysis), and positively-charged arginine and lysine residues at the $\mathrm{C}$ terminus [43]. The gp48 $\mathrm{Rz}$ inner membrane protein has a single $\mathrm{N}$-terminal transmembrane domain based on TMHMM analysis. Gene 49, encoding the Rz1 outer membrane lipoprotein, overlaps with gene 48 in the +1 reading frame and extends downstream of the 48 stop codon by 148 base pairs (Figure 2). LipoP analysis predicts a signal peptidase II cleavage site in gp49 between residues 18 (alanine) and 19 (cysteine).

The SAR endolysin of JG068 has a very similar organization to that of $\phi K M V$. SignalP 3.0 predicts an $\mathrm{N}$-terminal signal sequence probability of 0.97 for gp47 (later versions of SignalP do not make the same prediction, likely because the C-region is absent). The gp47 Nterminus contains two signal sequence regions followed by three putative catalytic residues of the lysozyme domain. Residues 1-7, including a positively-charged histidine, lysine, and arginine, make up the N-region. Residues 8-25 make up the hydrophobic glycine- and alanine-rich $\mathrm{H}$ region, also predicted to be a transmembrane domain by OCTOPUS analysis. Using CD Search and BLASTP alignment with the $\phi K M V$ SAR endolysin, the putative lysozyme catalytic residues were identified as 27E, 36D, and 45T, all found immediately downstream of the H-region. As in $\phi K M V$, because the C-region is absent, the protein will not be cleaved by a signal peptidase upon secretion and will instead remain associated with the inner membrane until release into the periplasm [43].

Using inducible expression of the $\$ K M V$ SAR endolysin in $E$. coli, it was shown that this protein could decrease culture absorbance in the absence of a pinholin, but only if the $\mathrm{N}$-terminal signal sequence of the endolysin was present [43]. We performed a similar experiment using the JG068 SAR endolysin to further characterize the export mechanism and biological activity of this protein. To allow for tightly controlled inducible expression, we cloned gene 47 into pET22b (with [gp47] or without [gp47 $\Delta S S$ ] the putative signal sequence in the first 25 residues) and transformed these plasmids into E. coli BL21 (DE3)pLysS. When these cells (or a pET22b blank control) are subcultured, their growth rates prior to IPTG induction are similar based on optical density measurements at $600 \mathrm{~nm}\left(\mathrm{OD}_{600}\right.$; up to $3 \mathrm{~h}$ in Figure 4$)$. However, following induction, expression of gp47 is lethal to the cells as the $\mathrm{OD}_{600}$ decreases from $\sim 0.6$ at 3 hours to $\sim 0.45$ at 8 hours (black squares, Figure 4). A very different trend is observed for the blank control, gp47 $\triangle \mathrm{SS}$, and uninduced gp47 strains, where the $\mathrm{OD}_{600}$ increases from $\sim 0.6$ at 3 hours to $\sim 0.9$ at 8 hours, double that of the induced gp47 $\mathrm{OD}_{600}$ (Figure 4). As the lytic activity is dependent upon expression of not only the lysozyme domain but also the signal sequence, we can conclude that JG068 gp47 acts as a typical SAR endolysin in Gram-negative bacteria. While the classical endolysins of Bcep781/Bcep43 and BcepC6B have been functionally characterized $[15,45]$, this is the first experimental evidence for SAR endolysin activity in a BCC phage. As these proteins have also been identified in the Bcep22-like viruses [25,46], similar experiments may be used to confirm the activity of SAR endolysins in these phages as well.

\section{In vivo activity}

The Galleria mellonella (greater wax moth) larvae model is commonly used to assess both strain virulence and phage therapy efficacy for members of the BCC, particularly B. cenocepacia $[10,11,18]$. Although this model is less complex than a mammalian system, it shows positive correlation with both mouse and rat models of infection [18]. To determine if JG068 possesses lytic activity against 


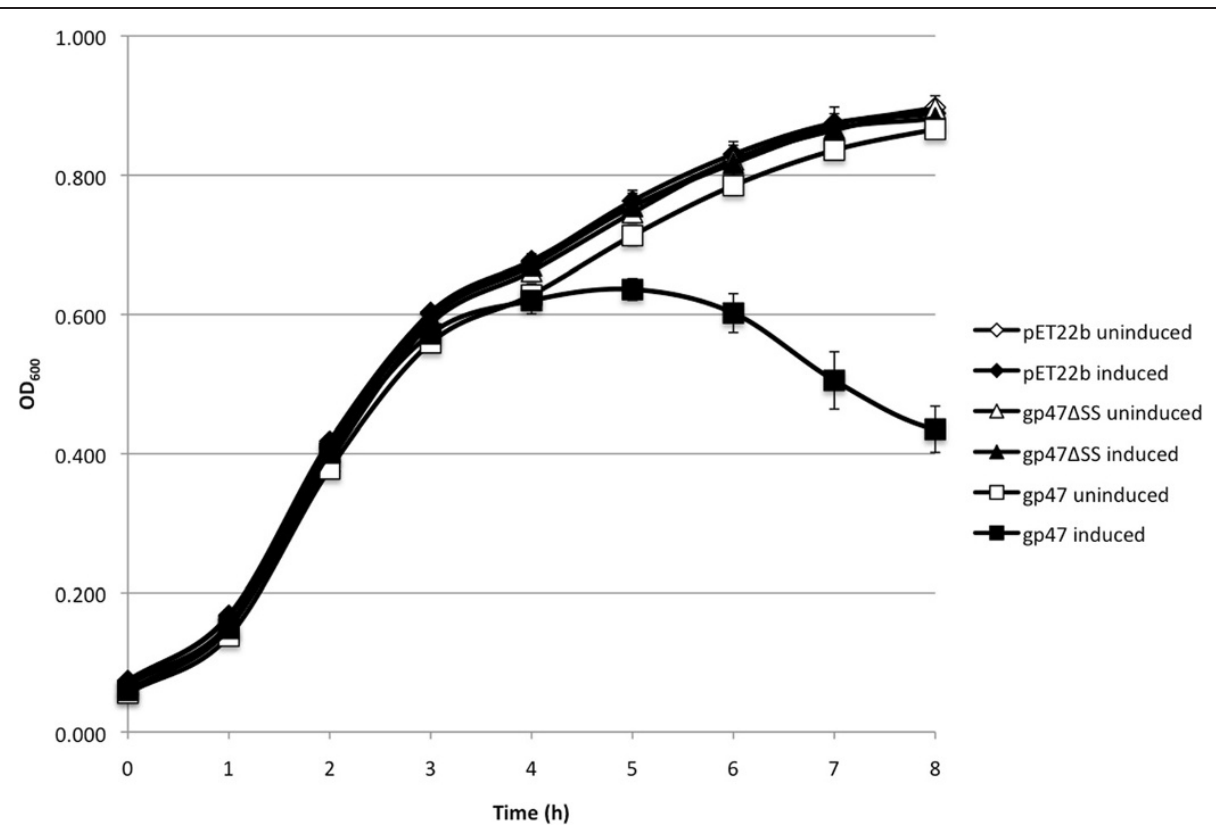

Figure 4 Signal sequence-dependent lytic activity of the gp47 SAR endolysin expressed in E. coli BL21(DE3)pLysS. Cells carrying pET22b or expressing either gp47 or gp47 lacking the putative signal sequence (gp47 $\Delta S \mathrm{SS})$ were subcultured and incubated with shaking at $37^{\circ} \mathrm{C}$. Cells were induced with $1 \mathrm{mM}$ IPTG (final concentration) at $3 \mathrm{~h}\left(\mathrm{OD}_{600} \sim 0.6\right)$.

B. cenocepacia in vivo, we infected G. mellonella larvae with $3.7 \times 10^{3}$ colony forming units (CFU) of K56-2 and treated with endotoxin-removed JG068 at a multiplicity of infection (MOI) of $350\left(1.3 \times 10^{6}\right.$ plaque forming units $[\mathrm{PFU}])$. For infected, untreated controls, no larvae survived after 72 hours (Figure 5, left). Those larvae that received only JG068 remained healthy over the course of the experiment (Figure 5, centre), indicating that phage treatment produced no harmful effects. For infected, treated larvae, JG068 administration significantly increased survival to an average of 77\% (from 0\% in untreated controls) (Figure 5, right). In a previous study, the putatively virulent phage
KS12 was the most effective for immediate treatment of K56-2 infection in the G. mellonella model, resulting in $93 \pm 12 \%$ survival $(\mathrm{MOI}=5000)$ or $57 \pm 6 \%$ survival $(\mathrm{MOI}=500)$ [10]. Based on the G. mellonella data presented in Figure 5, JG068 is almost as effective as a significantly larger dose of KS12, indicating that JG068 is highly active in vivo.

\section{Conclusions}

One of the greatest challenges in BCC phage therapy development is the identification of phages with a broad, clinically relevant host range that are free of virulence

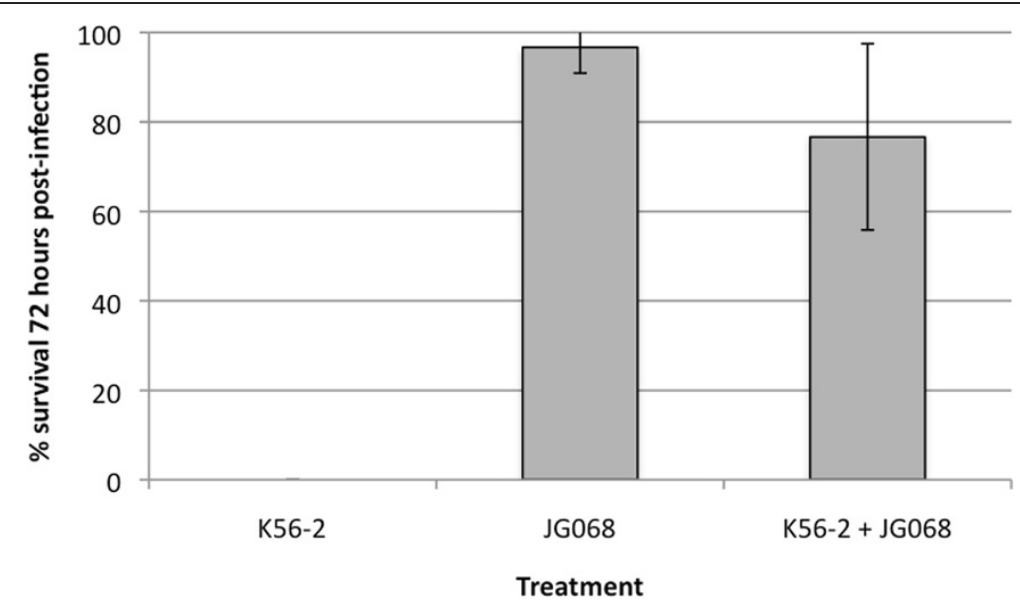

Figure 5 In vivo activity of JG068 against B. cenocepacia K56-2. G. mellonella larvae were infected with K56-2 and treated with endotoxinremoved JG068 at a multiplicity of infection (MOI) of 350. Survival was assessed 72 hours post-infection. 
genes, obligately lytic, and active in vivo. Our characterization of the podovirus JG068 indicates that it is a rare example of a $B C C$ phage that satisfies each of these requirements. JG068 infects strains of B. multivorans, $B$. cenocepacia (interacting with the LPS core as a receptor in K56-2 and PC184), B. stabilis, and B. dolosa. It is the first $\mathrm{BCC}$ virus to be identified as a member of the Autographivirinae subfamily and $\phi K M V$-like phages genus. The 41,604 bp genome sequence has a structure similar to that of other Autographivirinae chromosomes, with DTRs and genes encoding DNA-binding, morphogenesis, and lysis proteins expressed in the forward direction from phage and host promoters. JG068 lacks virulence genes, is obligately lytic, and encodes a functional SAR endolysin, the first to be experimentally verified for the BCC. Administration of JG068 to B. cenocepacia K562-infected G. mellonella larvae significantly decreases larval mortality, providing the first evidence that sequenced, obligately lytic $\mathrm{BCC}$ phages are active against B. cenocepacia in vivo. Given these characteristics, further study is warranted regarding the development of JG068 into an active antimicrobial for use in CF patients.

\section{Methods}

\section{Bacterial strains and culture conditions}

BCC strains were grown aerobically at $30^{\circ} \mathrm{C}$ overnight on half-strength Luria-Bertani ( $1 \frac{1}{2}$ LB) solid agar or agarose plates or in $1 / 2$ LB broth. Strains used for host range testing and phage propagation are members of the original and updated BCC experimental strain panels $[19,20]$. K56-2 LPS mutants $[27,28]$ were grown at $30^{\circ} \mathrm{C}$ on $1 / 2$ LB plates or in $1 / 2$ LB broth containing $100 \mathrm{mg} / \mathrm{l}$ trimethoprim. E. coli DH5 $\alpha$ transformed with pUC19 or pET22b was grown at $37^{\circ} \mathrm{C}$ on LB plates containing 100 $\mathrm{mg} / \mathrm{l}$ ampicillin. E. coli BL21(DE3)pLysS was grown at $37^{\circ} \mathrm{C}$ in LB broth containing $25 \mathrm{mg} / \mathrm{l}$ chloramphenicol or, if transformed with pET22b, $25 \mathrm{mg} / \mathrm{l}$ chloramphenicol and $100 \mathrm{mg} / \mathrm{l}$ ampicillin.

\section{Phage propagation, host range analysis, lysogeny screen, and electron microscopy}

JG068 was isolated from a sewage plant in Steinhof near Braunschweig in Germany following an enrichment protocol previously described [47]. For propagation of JG068, $100 \mu \mathrm{l}$ high-titre phage stock and $100 \mu \mathrm{l} \mathrm{BCC}$ liquid culture were combined and incubated 20 minutes at room temperature, mixed with $3 \mathrm{ml} 0.7 \% 1 / 2 \mathrm{LB}$ agar or $0.6 \% 1 / 2$ LB agarose, overlaid on a $1 / 2$ LB plate, and incubated at $30^{\circ} \mathrm{C}$ overnight. High-titre stocks were made in modified suspension medium (modified SM; $50 \mathrm{mM}$ Tris- $\mathrm{HCl}$ [pH 7.5], $100 \mathrm{mM} \mathrm{NaCl}, 10 \mathrm{mM} \mathrm{MgSO}_{4}$ ). Phage plates were overlaid with $3 \mathrm{ml}$ modified $\mathrm{SM}$ and incubated $>1 \mathrm{~h}$ at room temperature on a platform rocker. The supernatant was recovered, pelleted by centrifugation for $2 \mathrm{~min}$ at $10,000 \times \mathrm{g}$, filter-sterilized using a Millex-HA $0.45 \mu \mathrm{m}$ syringe-driven filter unit (Millipore, Billerica, MA), and stored at $4^{\circ} \mathrm{C}$.

Spot testing was used for preliminary host range analysis. Soft-agar overlays containing $100 \mu \mathrm{l}$ BCC liquid culture were allowed to solidify for $\geq 10$ minutes at room temperature, spotted with $10 \mu \mathrm{l}$ drops of high-titer JG068 stock, and assayed for clearing and/or plaque formation after incubation at $30^{\circ} \mathrm{C}$ overnight. Strains that showed phage susceptibility in this assay were re-tested in soft-agar overlays containing both the strain and JG068. The host ranges for LPS mutants of K56-2 [27,28] and PC184 [Abdu, unpublished data] were tested similarly. Efficiency of plating (EOP) values were determined as previously described [46].

To assay for JG068-lysogenized K56-2, JG068 and K56-2 were plated in agar overlays at a multiplicity of infection of $10^{\circ}$ and incubated at $30^{\circ} \mathrm{C}$ overnight. To recover surviving cells, plates were overlaid with $3 \mathrm{ml}$ sterile water and incubated $1 \mathrm{~h}$ at room temperature on a platform rocker. Cells were pelleted by centrifugation for $2 \mathrm{~min}$ at $10,000 \times \mathrm{g}$, washed and resuspended in sterile water, and plated to obtain isolated colonies. Colonies were struck out onto $1 / 2 \mathrm{LB}$ plates and spotted with separate $10 \mu \mathrm{l}$ drops of high-titer JG068 stock and high-titer KS12 stock. Isolates were scored as sensitive or insensitive compared to a sensitive wildtype K56-2 control that was lysed by both phage stocks. A subset of resistant isolates was replated and PCRscreened for lysogeny using JG068-specific primers (9F: GAACATCGGTAACGTCGTCAAGG; 9R: GGCGTGA CGAACAGCTTGGC). TopTaq DNA polymerase and buffers (Qiagen, Hilden, Germany) were used according to the manufacturer's instructions (template: $1 \mu$ l overnight culture incubated $5 \mathrm{~min}$ at $100^{\circ} \mathrm{C}$ ).

For electron microscopy, phage stocks were prepared as described above with the following modifications: agarose plates and soft agarose were used for overlays, sterile water was used in place of modified SM, and a $0.22 \mu \mathrm{m}$ filter was used for syringe-driven filtration. A carbon-coated copper grid was incubated with lysate for $5 \mathrm{~min}$ and stained with $2 \%$ phosphotungstic acid for $30 \mathrm{~s}$. Transmission electron micrographs were captured using a Philips/FEI (Morgagni) transmission electron microscope with charge-coupled device camera at $80 \mathrm{kV}$ (University of Alberta Department of Biological Sciences Advanced Microscopy Facility). The capsid diameter (mean \pm standard deviation) was calculated using Microsoft Excel based on measurements from nine individual virions.

\section{Phage DNA isolation, RFLP analysis, and sequencing}

Phage DNA was isolated using a modified version of a Wizard DNA Clean-Up protocol [48]. Ten milliliters of filter-sterilized JG068 lysate (propagated using K56-2 on agarose medium) was treated with $10 \mu \mathrm{l}$ DNase I (Thermo 
Scientific, Waltham, MA), $100 \mu \mathrm{l} 100 \mathrm{x}$ DNase I buffer (1 M Tris- $\mathrm{HCl}, 0.25 \mathrm{M} \mathrm{MgCl}_{2}, 10 \mathrm{mM} \mathrm{CaCl}_{2}$ ), and $6 \mu \mathrm{l}$ RNase (Thermo Scientific) and incubated $1 \mathrm{~h}$ at $37^{\circ} \mathrm{C}$ to degrade the bacterial nucleic acids. Four hundred microliters of $0.5 \mathrm{M}$ EDTA and $25 \mu \mathrm{l}$ of $20 \mathrm{mg} / \mathrm{ml}$ proteinase $\mathrm{K}$ (Applied Biosystems, Carlsbad, CA) were added and incubated $1 \mathrm{~h}$ at $55^{\circ} \mathrm{C}$ to inactivate DNase I. After cooling to room temperature, the lysate was added to $8.4 \mathrm{~g}$ of guanidine thiocyanate and briefly mixed. One milliliter of warmed, resuspended Wizard DNA Clean-Up Resin (Promega Corporation, Madison, WI) was added to the mixture and mixed by inverting for 15 minutes to allow for release of the phage DNA and binding to the resin. The mixture was pelleted by centrifugation at room temperature for $10 \mathrm{~min}$ at 5,000 $\mathrm{x}$ g and the supernatant was drawn off until $\sim 5 \mathrm{ml}$ remained. This mixture was resuspended by swirling, transferred into an empty syringe barrel attached to a Wizard Minicolumn (Promega Corporation), and pushed into the column. The column was then washed with $2 \mathrm{ml} \mathrm{80 \%} \mathrm{isopropanol} \mathrm{and} \mathrm{dried} \mathrm{by}$ centrifugation for $2 \mathrm{~min}$ at 10,000 x g. JG068 DNA was eluted from the column following addition of $100 \mu \mathrm{l}$ of $80^{\circ} \mathrm{C}$ nuclease-free water (Integrated DNA Technologies, Coralville, IA), incubation for $1 \mathrm{~min}$, and centrifugation for $\geq 20 \mathrm{~s}$ at $10,000 \mathrm{x}$ g.

Phage and plasmid DNA were quantified using a NanoDrop 2000c spectrophotometer (Thermo Scientific). For shotgun cloning, JG068 EcoRI fragments were purified using a GENECLEAN III kit (MP Biomedicals, Santa Ana, CA), ligated into pUC19, and transformed into E. coli $\mathrm{DH} 5 \alpha$ (Invitrogen, Carlsbad, CA). Plasmids were purified using the GeneJET Plasmid Miniprep kit (Thermo Scientific) and sequenced using a 3730 DNA Analyzer (Applied Biosystems) by the University of Alberta Department of Biological Sciences Molecular Biology Service Unit (MBSU). Sequences were edited and assembled using Geneious [49].

The complete JG068 genome sequence was determined with the assistance of the MBSU using an Ion Torrent PGM (Applied Biosystems) and assembled using SeqMan NGen (DNASTAR, Madison, WI). Ambiguous regions in the assembly were resequenced using Sanger sequencing from EcoRI clones (for internal fragments) or PCR products (for terminal fragments). Chromosomal termini were identified using primers within the left direct terminal repeat (DTR), extending to the left end (IL: CAACCCTGTACAGCCGACCC), outside of the left DTR, extending to the left end (OL: CCTTGCTCTAT CTACCATGTTCCGC), within the right DTR, extending to the right end (IR: TGTGGATAGGGCGAAGTCT GAAGC), and outside of the right DTR, extending to the right end (OR: CTCCGACGAAGCATCCGC). Primers were used to directly sequence the JG068 DNA and sequence alignment was used to identify the loci where sequence intensity dropped by $50 \%$ (for primers IL and IR) or $100 \%$ (for primers OL and OR). The JG068 sequence has been deposited in GenBank [GenBank: KC853746].

\section{Bioinformatics analysis}

Open reading frames (ORFs) were identified using GeneMark.hmm for prokaryotes [54] and annotated using BLASTP [55], HHpred [56], and CD-Search [57]. Gene 49, which has a start codon within the last third of gene 48 , was identified using ORF Finder [58]. The replication origin and terminus were predicted using a GC-skew plot generated by GenSkew [59]. Genome restriction profiles were predicted using NEBcutter [60]. Whole genome comparisons were performed using CoreGenesUniqueGenes (CGUG) with a cutoff score of 75 [35,37]. Screening for bacterial toxins was performed using BTXpred [61]. Bacterial promoters, phage promoters, and rho-independent terminators were identified using prokaryotic Neural Network Promoter Prediction with a cutoff of 0.95 [50], PHIRE [51], and TransTermHP [53] on the PePPER server [62], respectively. Sequence logos were constructed using WebLogo [52]. Transmembrane domains were predicted using TMHMM [63] and OCTOPUS [64]. Lysis protein signal sequences were identified using SignalP 3.0 [65] and LipoP [66].

\section{SAR endolysin expression}

To assess the activity of the gp47 SAR endolysin, gene 47 including the signal sequence (bp 40,232 - 40,753; NdeI-SS-F: ATAATAACATATGCACCCCATCGTCAA GCGAG; HindIII-R: AAAAAGCTTCTATCGCCGGA TACCAGCAACG) or excluding the signal sequence (bp 40,307 - 40,753; NdeI- $\triangle$ SS-F: TAATAACATATGG ACGAGGGTATCCGGAACGTC; HindIII-R: as above) was PCR amplified using KAPA HiFi HotStart ReadyMix (Kapa Biosystems, Woburn, MA) and ligated in-frame into pET22b. These constructs were separately transformed into $E$. coli $\mathrm{DH} 5 \alpha$, sequenced to verify that the inserts were correct, and transformed into E. coli BL21 (DE3)pLysS using a standard protocol [67]. A pET22b blank control plasmid was isolated from E. coli MC4100 and transformed similarly into BL21(DE3)pLysS. To assay endolysin activity in E. coli, $5 \mathrm{ml}$ liquid cultures of the three strains (in triplicate) were each subcultured into six wells of a 96 well plate by adding $10 \mu$ l culture to $190 \mu \mathrm{l} \mathrm{LB}$ broth containing $25 \mathrm{mg} / \mathrm{l}$ chloramphenicol and $100 \mathrm{mg} / \mathrm{l}$ ampicillin. The plate was then covered with plastic wrap and incubated with shaking at $37^{\circ} \mathrm{C}$. Optical density measurements at $600 \mathrm{~nm}\left(\mathrm{OD}_{600}\right)$ were measured at $1 \mathrm{~h}$ intervals with a Wallac $1420 \mathrm{VICTOR}^{2}$ multilabel counter (PerkinElmer, Waltham, MA). At $3 \mathrm{~h}\left(\mathrm{OD}_{600} \sim\right.$ 0.6), half of the samples were induced with IPTG (1 mM final concentration) and optical density measurements 
continued at $1 \mathrm{~h}$ intervals up to $8 \mathrm{~h}$. Averages and standard deviations were calculated using Microsoft Excel.

\section{Galleria mellonella assays}

G. mellonella infection and treatment assays were performed as described previously [10] with modifications. One milliliter of a $16 \mathrm{~h} \mathrm{K56-2}$ overnight culture was pelleted by centrifugation for $2 \mathrm{~min}$ at $10,000 \times \mathrm{g}$, resuspended in $1 \mathrm{ml} \mathrm{MgSO}_{4}$-ampicillin solution $(10 \mathrm{mM}$ $\mathrm{MgSO}_{4}, 1.2 \mathrm{mg} / \mathrm{ml}$ ampicillin), and diluted in this solution to $1: 10^{4}$. High-titre JG068 lysate was passaged through a Detoxi-Gel Endotoxin Removing Column (Thermo Scientific) and supplemented with ampicillin. Larvae (RECORP Inc., Georgetown, ON) were stored at $4^{\circ} \mathrm{C}$ and warmed to room temperature prior to injection with a $250 \mu$ syringe with repeating dispenser (Hamilton Company, Reno, NV). In the left hindmost proleg, $5 \mu$ l of the diluted K56-2 suspension $\left(3.7 \times 10^{3} \mathrm{CFU} / 5 \mu \mathrm{l}\right)$ was injected into ten infected/treated larvae and ten infected/untreated larvae and $5 \mu \mathrm{l}$ of $\mathrm{MgSO}_{4}$-ampicillin solution was injected into ten uninfected/treated larvae. In the adjacent left proleg, $5 \mu \mathrm{l}$ of the JG068 lysate $\left(1.3 \times 10^{6} \mathrm{PFU} / 5 \mu \mathrm{l}\right)$ was injected into ten infected/treated larvae and ten uninfected/treated larvae and $5 \mu \mathrm{l}$ of $\mathrm{MgSO}_{4}$-ampicillin solution was injected into ten infected/untreated larvae. Larvae were placed into petri dishes, incubated aerobically at $30^{\circ} \mathrm{C}$ for $72 \mathrm{~h}$, and scored for survival. Experiments were repeated in triplicate. Averages and standard deviations were calculated using Microsoft Excel.

\section{Competing interests}

The authors declare that they have no competing interests.

\section{Authors' contributions}

$\mathrm{KHL}$ and $\mathrm{AHA}$ carried out the electron microscopy and sequenced and assembled the JG068 genome. KHL annotated the genome, performed bioinformatics analyses, and drafted the manuscript. AHA determined the BCC and LPS mutant host ranges, performed the SAR endolysin and G. mellonella experiments, and edited the manuscript. MS isolated JG068. JJD planned, supervised, and coordinated the study and edited the manuscript. All authors read and approved the final manuscript.

\section{Acknowledgements}

The authors would like to thank Miguel Valvano (University of Western Ontario) for providing the K56-2 LPS mutants, Colin Coros and Michelle Miller (Delta Genomics), Arlene Oatway (University of Alberta Department of Biological Sciences Advanced Microscopy Facility), and the staff of the University of Alberta Department of Biological Sciences Molecular Biology Service Unit. JJD gratefully acknowledges funding from the Canadian Institutes of Health Research and Cystic Fibrosis Canada.

\section{Author details}

'Department of Biological Sciences, 6-008 Centennial Centre for Interdisciplinary Science, University of Alberta, Edmonton, AB T6G 2E9 Canada. ${ }^{2}$ Institute of Microbiology, Technische Universität Braunschweig, Spielmannstr. 7, 38106 Braunschweig, Germany.

Received: 18 April 2013 Accepted: 9 August 2013

Published: 27 August 2013

\section{References}

1. Falagas ME, Bliziotis IA, Kasiakou SK, Samonis G, Athanassopoulou P Michalopoulos A: Outcome of infections due to pandrug-resistant (PDR) Gram-negative bacteria. BMC Infect Dis 2005, 5:24.

2. Merril CR, Scholl D, Adhya SL: The prospect for bacteriophage therapy in Western medicine. Nat Rev Drug Discov 2003, 2:489-497.

3. Bruttin A, Brüssow $\mathrm{H}$ : Human volunteers receiving Escherichia coli phage T4 orally: a safety test of phage therapy. Antimicrob Agents Chemother 2005, 49:2874-2878.

4. Merabishvili M, Pirnay J-P, Verbeken G, Chanishvili N, Tediashvili M, Lashkhi N Glonti T, Krylov V, Mast J, Van Parys L, Lavigne R, Volckaert G, Mattheus W, Verween G, De Corte P, Rose T, Jennes S, Zizi M, De Vos D, Vaneechoutte M: Quality-controlled small-scale production of a well-defined bacteriophage cocktail for use in human clinical trials. PLOS ONE 2009, 4:e4944.

5. Rhoads DD, Wolcott RD, Kuskowski MA, Wolcott BM, Ward LS, Sulakvelidze A: Bacteriophage therapy of venous leg ulcers in humans: results of a phase I safety trial. J Wound Care 2009, 18:237-243.

6. Wright A, Hawkins CH, Änggård EE, Harper DR: A controlled clinical trial of a therapeutic bacteriophage preparation in chronic otitis due to antibiotic-resistant Pseudomonas aeruginosa; A preliminary report of efficacy. Clin Otolaryngol 2009, 34:349-357.

7. Mahenthiralingam E, Urban TA, Goldberg JB: The multifarious, multireplicon Burkholderia cepacia complex. Nat Rev Microbiol 2005, 3:144-156.

8. Zhou J, Chen Y, Tabibi S, Alba L, Garber E, Saiman L: Antimicrobial susceptibility and synergy studies of Burkholderia cepacia complex isolated from patients with cystic fibrosis. Antimicrob Agents Chemother 2007, 51:1085-1088.

9. Adachi N, Tsukamoto S, Inoue Y, Azegami K: Control of bacterial seedling rot and seedling blight of rice by bacteriophage. Plant Dis 2012, 96:1033-1036.

10. Seed KD, Dennis JJ: Experimental bacteriophage therapy increases survival of Galleria mellonella larvae infected with clinically relevant strains of the Burkholderia cepacia complex. Antimicrob Agents Chemother 2009, 53:2205-2208.

11. Lynch KH, Seed KD, Stothard P, Dennis JJ: Inactivation of Burkholderia cepacia complex phage KS9 gp41 identifies the phage repressor and generates lytic virions. J Virol 2010, 84:1276-1288.

12. Carmody LA, Gill JJ, Summer EJ, Sajjan US, Gonzalez CF, Young RF, LiPuma JJ: Efficacy of bacteriophage therapy in a model of Burkholderia cenocepacia pulmonary infection. J Infect Dis 2010, 201:264-271.

13. Lynch KH, Dennis JJ: Cangene gold medal award lecture - Genomic analysis and modification of Burkholderia cepacia complex bacteriophages. Can J Microbio/ 2012, 58:221-235.

14. Lynch KH, Dennis JJ: Genomics of Burkholderia phages. In Burkholderia: From Genomes to Function. Edited by Coenye T, Mahenthiralingam E. Hethersett: Horizon Scientific Press. In press.

15. Summer EJ, Gonzalez CF, Bomer M, Carlile T, Embry A, Kucherka AM, Lee J, Mebane L, Morrison WC, Mark L, King MD, LiPuma JJ, Vidaver AK, Young R: Divergence and mosaicism among virulent soil phages of the Burkholderia cepacia complex. J Bacteriol 2006, 188:255-268.

16. Robinson SM, Hall J, Das A, Rosenbloom A, Gonzalez C, Young R, Summer EJ: M-015. Genomic analysis of virulent soil phages of Burkholderia. http://ieg.ou. edu/asm2006/data/papers/M_015.htm.

17. Pirnay J-P, Verbeken G, Rose T, Jennes S, Zizi M, Huys I, Lavigne R, Merabishvili M, Vaneechoutte M, Buckling A, De Vos D: Introducing yesterday's phage therapy in today's medicine. Future Virol 2012, 7:379-390.

18. Seed KD, Dennis JJ: Development of Galleria mellonella as an alternative infection model for the Burkholderia cepacia complex. Infect Immun 2008, 76:1267-1275.

19. Mahenthiralingam E, Coenye T, Chung JW, Speert DP, Govan JRW Taylor P, Vandamme P: Diagnostically and experimentally useful panel of strains from the Burkholderia cepacia complex. J Clin Microbiol 2000, 38:910-913.

20. Coenye T, Vandamme P, LiPuma JJ, Govan JRW, Mahenthiralingam E: Updated version of the Burkholderia cepacia complex experimental strain panel. J Clin Microbiol 2003, 41:2797-2798.

21. Broad Institute: Burkholderia dolosa database. http://www.broadinstitute.org/ annotation/genome/burkholderia_dolosa.

22. Seed KD, Dennis JJ: Isolation and characterization of bacteriophages of the Burkholderia cepacia complex. FEMS Microbiol Lett 2005, 251:273-280. 
23. Goudie AD, Lynch KH, Seed KD, Stothard P, Shrivastava S, Wishart DS, Dennis JJ: Genomic sequence and activity of KS10, a transposable phage of the Burkholderia cepacia complex. BMC Genomics 2008, 9:615.

24. Lynch KH, Stothard P, Dennis JJ: Genomic analysis and relatedness of P2-like phages of the Burkholderia cepacia complex. BMC Genomics 2010, 11:599.

25. Lynch KH, Stothard P, Dennis JJ: Characterization of DC1, a broad-host-range Bcep22-like podovirus. App/ Environ Microbio/ 2012, 78:889-891.

26. Lynch KH, Stothard P, Dennis JJ: Comparative analysis of two phenotypically-similar but genomically-distinct Burkholderia cenocepaciaspecific bacteriophages. BMC Genomics 2012, 13:223.

27. Loutet SA, Flannagan RS, Kooi C, Sokol PA, Valvano MA: A complete lipopolysaccharide inner core oligosaccharide is required for resistance of Burkholderia cenocepacia to antimicrobial peptides and bacterial survival in vivo. J Bacteriol 2006, 188:2073-2080.

28. Ortega X, Silipo A, Saldfas MS, Bates CC, Molinaro A, Valvano MA: Biosynthesis and structure of the Burkholderia cenocepacia K56-2 lipopolysaccharide core oligosaccharide: Truncation of the core oligosaccharide leads to increased binding and sensitvity to polymyxin B. J Biol Chem 2009, 284:21738-21751.

29. Ackermann $\mathrm{H}-\mathrm{W}$ : Frequency of morphological phage descriptions in the year 2000. Arch Virol 2001, 146:843-857.

30. Casjens SR, Gilcrease EB: Determining DNA packaging strategy by analysis of the termini of the chromosomes in tailed-bacteriophage virions. Methods Mol Biol 2009, 502:91-111.

31. Summer EJ: Preparation of a phage DNA fragment library for whole genome shotgun sequencing. Methods Mol Biol 2009, 502:27-46.

32. Lavigne R, Burkal'tseva MV, Robben J, Sykilinda NN, Kurochkina LP, Grymonprez B, Jonckx B, Krylov VN, Mesyanzhinov W, Volckaert G: The genome of bacteriophage $\varphi \mathrm{KMV}$, a T7-like virus infecting Pseudomonas aeruginosa. Virology 2003, 312:49-59.

33. Ceyssens P-J, Lavigne R, Mattheus W, Chibeu A, Hertveldt K, Mast J, Robben J, Volckaert G: Genomic analysis of Pseudomonas aeruginosa phages LKD16 and LKA1: establishment of the $\varphi$ KMV subgroup within the T7 supergroup. J Bacterio/ 2006, 188:6924-6931.

34. Adriaenssens EM, Ceyssens P-J, Dunon V, Ackermann H-W, Van Vaerenbergh J, Maes M, De Proft M, Lavigne R: Bacteriophages LIMElight and LIMEzero of Pantoea agglomerans, belonging to the " $\varphi$ KMV-like viruses". Appl Environ Microbiol 2011, 77:3443-3450.

35. Lavigne R, Seto D, Mahadevan P, Ackermann H-W, Kropinski AM: Unifying classical and molecular taxonomic classification: analysis of the Podoviridae using BLASTP-based tools. Res Microbiol 2008, 159:406-414

36. Abbasifar R, Kropinski AM, Sabour PM, Ackermann H-W, Alanis Villa A, Abbasifar A, Griffiths MW: The genome of Cronobacter sakazakii bacteriophage vB_CsaP_GAP227 suggests a new genus within the Autographivirinae. Genome Announc 2013, 1:e00122-12.

37. Mahadevan P, King JF, Seto D: CGUG: in silico proteome and genome parsing tool for the determination of "core" and unique genes in the analysis of genomes up to ca. 1.9 Mb. BMC Res Notes 2009, 2:168.

38. Molineux IJ: The T7 Group. In The Bacteriophages. 2nd edition. Edited by Calendar R. New York: Oxford University Press; 2006:277-301.

39. Casjens S: Prophages and bacterial genomics: What have we learned so far? Mol Microbiol 2003, 49:277-300

40. Kawasaki T, Shimizu M, Satsuma H, Fujiwara A, Fujie M, Usami S, Yamada T: Genomic characterization of Ralstonia solanacearum phage $\varphi R S B 1$, a T7like wide-host-range phage. J Bacterio/ 2009, 191:422-427.

41. Lavigne R, Villegas A, Kropinksi AM: In silico characterization of DNA motifs with particular reference to promoters and terminators. Methods Mol Biol 2009, 502:113-129

42. Lavigne $R$, Noben JP, Hertveldt $K$, Ceyssens P-J, Briers $Y$, Dumont $D$, Roucourt B, Krylov VN, Mesyanzhinov W, Robben J, Volckaert G: The structural proteome of Pseudomonas aeruginosa bacteriophage $\varphi \mathrm{KMV}$. Microbiology 2006, 152:529-534.

43. Briers $Y$, Peeters LM, Volckaert G, Lavigne R: The lysis cassette of bacteriophage $\varphi$ KMV encodes a signal-arrest-release endolysin and a pinholin. Bacteriophage 2011, 1:25-30.

44. Dobbins AT, George M Jr, Basham DA, Ford ME, Houtz JM, Pedulla ML, Lawrence JG, Hatfull GF, Hendrix RW: Complete genomic sequence of the virulent Salmonella bacteriophage SP6. J Bacterio/ 2004, 186:1933-1944.

45. Walmagh M, Boczkowska B, Grymonprez B, Briers Y, Drulis-Kawa Z, Lavigne R: Characterization of five novel endolysins from
Gram-negative infecting bacteriophages. Appl Microbiol Biotechnol 2012: $10.1007 /$ s00253-012-4294-7.

46. Gill JJ, Summer EJ, Russell WK, Cologna SM, Carlile TM, Fuller AC, Kitsopoulos K, Mebane LM, Parkinson BN, Sullivan D, Carmody LA Gonzalez CF, LiPuma JJ, Young R: Genomes and characterization of phages Bcep22 and BceplL02, founders of a novel phage type in Burkholderia cenocepacia. J Bacteriol 2011, 193:5300-5313.

47. Garbe J, Bunk B, Rohde M, Schobert M: Sequencing and characterization of Pseudomonas aeruginosa phage JG004. BMC Microbio/ 2011, 11:102.

48. Promega Corporation: DNA Isolation From Lambda Lysates Using the Wizard ${ }^{\circledR}$ DNA Clean-Up System. http://www.promega.ca/resources/articles/pubhub/ enotes/dna-isolation-from-lambda-lysates-using-the-wizard-dna-cleanup-system.

49. Drummond AJ, Ashton B, Buxton S, Cheung M, Cooper A, Duran C, Heled J, Kearse M, Markowitz S, Moir R, Stones-Havas S, Sturrock S, Swidan F, Thierer T, Wilson A: Geneious v5.6. http://www.geneious.com.

50. Reese MG: Application of a time-delay neural network to promoter annotation in the Drosophila melanogaster genome. Comput Chem 2001, 26:51-56.

51. Lavigne R, Sun WD, Volckaert G: PHIRE, a deterministic approach to reveal regulatory elements in bacteriophage genomes. Bioinformatics 2004, 20:629-635

52. Crooks GE, Hon G, Chandonia JM, Brenner SE: WebLogo: a sequence logo generator. Genome Res 2004, 14:1188-1190.

53. Kingsford CL, Ayanbule K, Salzberg SL: Rapid, accurate, computational discovery of Rho-independent transcription terminators illuminates their relationship to DNA uptake. Genome Biol 2007, 8:R22.

54. Lukashin AV, Borodovsky M: GeneMark.hmm: New solutions for gene finding. Nucleic Acids Res 1998, 26:1107-1115.

55. Altschul SF, Madden TL, Schäffer AA, Zhang J, Zhang Z, Miller W, Lipman DJ: Gapped BLAST and PSI-BLAST: A new generation of protein database search programs. Nucleic Acids Res 1997, 25:3389-3402.

56. Söding J, Biegert A, Lupas AN: The HHpred interactive server for protein homology detection and structure prediction. Nucleic Acids Res 2005, 33:W244-W248.

57. Marchler-Bauer A, Bryant SH: CD-Search: Protein domain annotations on the fly. Nucleic Acids Res 2004, 32:W327-W331.

58. NCBI: ORF Finder. http://www.ncbi.nlm.nih.gov/projects/gorf

59. GenSkew - visualization of nucleotide skew in genome sequences. http:// genskew.csb.univie.ac.at.

60. Vincze T, Posfai J, Roberts RJ: NEBcutter: A program to cleave DNA with restriction enzymes. Nucleic Acids Res 2003, 31:3688-3691.

61. Saha S, Raghava GP: BTXpred: prediction of bacterial toxins. In Silico Biol 2007, 7:405-412.

62. Transcription Terminator Prediction. http://pepper.molgenrug.nl/index.php/ pepper-tools/terminator-predictie

63. Krogh A, Larsson B, von Heijne G, Sonnhammer ELL: Predicting transmembrane protein topology with a hidden Markov model: Application to complete genomes. J Mol Biol 2001, 305:567-580.

64. Viklund $\mathrm{H}$, Elofsson A: OCTOPUS: Improving topology prediction by two-track ANN-based preference scores and an extended topological grammar. Bioinformatics 2008, 24:1662-1668.

65. Bendtsen JD, Nielsen H, von Heijne G, Brunak S: Improved prediction of signal peptides: SignalP 3.0. J Mol Biol 2004, 340:783-795.

66. Juncker AS, Willenbrock H, von Heijne G, Brunak S, Nielsen H, Krogh A: Prediction of lipoprotein signal peptides in Gram-negative bacteria. Protein Sci 2003, 12:1652-1662.

67. Silhavy TJ, Berman ML, Enquist LW: Experiments with Gene Fusions. Cold Spring Harbor Laboratory: Cold Spring Harbor; 1984.

doi:10.1186/1471-2164-14-574

Cite this article as: Lynch et al:: Genomic characterization of JG068, a novel virulent podovirus active against Burkholderia cenocepacia. BMC Genomics 2013 14:574. 